\title{
A Proposed Decision Support System for Location Selection using Fuzzy Quality Function Deployment
}

\author{
R. Tavakkoli-Moghaddam ${ }^{1}$, S. Hassanzadeh Amin ${ }^{2}$ and G. Zhang ${ }^{2}$ \\ ${ }^{1}$ Department of Industrial Engineering, College of Engineering, University of Tehran, \\ 2Department of Industrial and Manufacturing Systems Eng., University of Windsor, \\ ${ }^{1}$ Iran \\ ${ }^{2}$ Canada
}

\section{Introduction}

Location selection is a multi-criteria decision making (MCDM) problem that includes both tangible and intangible factors (Kahraman et al., 2003). Location problems involve the determination of the location of one or more new facilities in one or several potential sites. Obviously, the number of sites should be at least equal to the number of new facilities being located (Heragu, 2006). The majority of research approaches for location selection focus on heuristics (Berman et al., 2001) and mathematical programming, such as integer programming (Melkote \& Daskin, 2001), dynamic programming (Canel et al., 2001), and nonlinear programming (Nanthavanij \& Yenradee, 1999). However, the mathematical programming cannot consider qualitative criteria. Moreover, the decision makers do not contribute in decision making process, and the roll of experience is ignored. Another problem is appeared when there are a lot of alternatives. In this condition, the decision makers prefer to select a group of alternatives, called pre-qualified alternatives. Then, decision makers will select the best alternative from the new group. A pre-qualification stage decreases time and costs of the decision making process. In addition, the characteristics of products affect on the location of factories. For instance, the location of a factory that manufactures heavy products should be different from ordinary factories. However in previous researches, the relationship between location criteria and product criteria is ignored.

In this chapter, we propose a new model for location selection consisting of two phases. In the first phase (i.e., pre-qualification stage), we propose a novel fuzzy based decision making model to take into account both qualitative and quantitative criteria. In the second phase (i.e., final selection), quality function deployment (QFD) is applied to select the best location to establish a factory. Not only QFD is a planning tool used in quality control, but also it is a useful tool in decision making. QFD enables us to consider the relationship between product criteria and location criteria to select the best location. This feature distinguishes QFD from other decision making tools. Moreover, the fuzzy sets theory, linguistic variables, and triangular fuzzy numbers are utilized. A major contribution of the fuzzy sets theory is its capability of representing vague data. In other words, it can 
overcome the uncertainty in human's judgments. Finally, an illustrative example is conducted to show the phases of location selection. In this example, eight potential alternatives (locations) are assessed in the first phase in order to select three alternatives. Then, fuzzy QFD is applied to select the best location. The implementation of the proposed model is easy and does not need any optimization background.

This chapter is organized as follows. Section 2 gives a literature review. Section 3 presents a description for the fuzzy sets theory. Section 4 describes the problem. Then, the proposed model is presented in Section 5. Furthermore, an illustrative example is given in Section 6. Finally, conclusions are provided in Section 7.

\section{Literature review}

Location selection is a multi-criteria decision making (MCDM) problem that includes both qualitative and quantitative metrics. In this section, a literature review is presented in two sections, called location selection and quality function deployment (QFD).

\subsection{Location selection}

In this section, we imply on the papers of location selection using MCDM techniques. Tzeng \& Chen (1999) proposed a location model based on a fuzzy multi-objective approach. This model helps in determining the optimal number and sites of fire stations at an international airport, and also determining the best location. Chen (2001) used triangular fuzzy numbers to select the best distribution location. Furthermore, he proposed a stepwise ranking procedure to rank fuzzy numbers. Kuo et al. (2002) proposed an algorithm for determining the location of a store. The model is based on fuzzy analytical hierarchy process (AHP). Kahraman et al. (2003) solved facility location problems using different solutions of fuzzy multi-attribute group decision-making. They compared four fuzzy models. Chou et al. (2008) presented a fuzzy multi-criteria decision making (FMCDM) model for location selection of the international tourist hotel based on triangular fuzzy numbers. Furthermore, they categorized hotels criteria as a hierarchy. Guneri et al. (2009) used the analytic network process (ANP) to select the best location. However, in all of these models the relationship between product characteristics and location criteria is ignored. QFD is a unique tool that can overcome this drawback.

\subsection{QFD}

Quality function deployment (QFD) has been widely used for numerous years. It was originated in Japan in 1970s and became increasingly popular in the western world in the 1980s (Houser \& Clausing, 1988). In general, it is used by many companies because of three reasons: (1) it saves design and development time, (2) it focuses on the satisfaction of customer, and (3) it improves communication at all levels of the organization (Myint, 2003). Although QFD has a lot of advantages, it also has some drawbacks, such as the amount of time required to implement QFD, and the qualitative and subjective decision-making process (Cohen, 1995; Bouchereau \& Rowlands, 2000). Because of the lack of precise information from customer requirements, QFD team members usually determine the relationships between customer requirements and engineering design requirements subjectively (Chen \& Weng, 2003). Fig. 1 shows the number of articles on QFD from 1999 until 2008, which is obtained by Scopus on 21 June 2009. The increasing trend shows that 
this field of study has a lot of opportunity for future research. QFD basically consists of four matrixes: namely planning matrix, designing matrix, operating matrix, and control matrix as shown in Fig. 2.

The house of quality (HOQ) is an important tool for QFD activities, containing information on "what"(customer requirements), "how" (design requirements), relationship between "what" and "how", and the relationship between the "how" factors themselves (Chen \& Ko, 2009). Fig. 3 illustrates a HOQ including customer requirements (CR), design requirements $(\mathrm{DR})$, parts requirements (PR), process operations (PO), and production characteristics (PC).

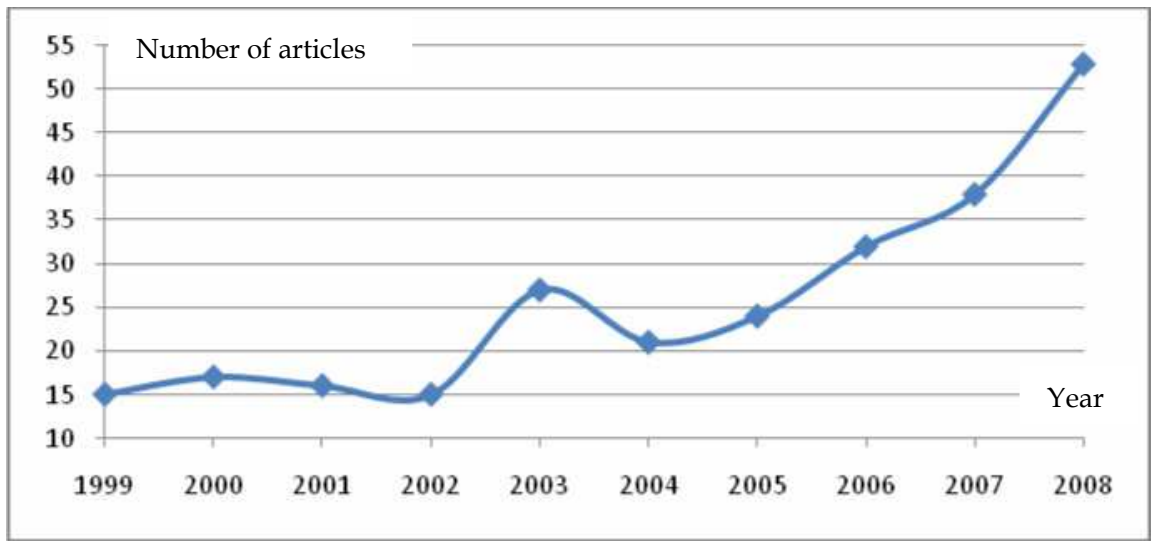

Fig. 1. Numbers of scientific articles in the HOQ or QFD

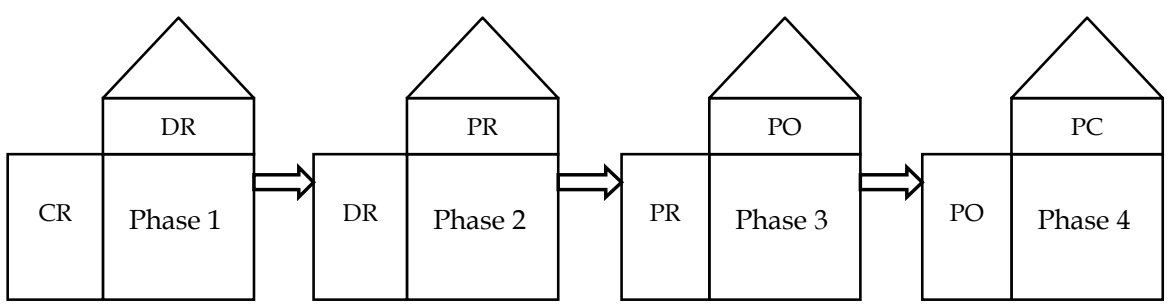

Fig. 2. QFD in four phases

Chan \& Wu (2002) presented a literature review for QFD. They also reviewed historical development of QFD, especially in Japan and USA. They categorized functional fields of QFD as product development, quality management, customer needs analysis, design, planning, decision-making, engineering, management, teamwork, timing, and costing. Sharma et al. (2008) reviewed a literature on the topic and application of QFD. They implied that intelligent quantitative methods, such as artificial neural networks, analytical heirarchy process (AHP) and fuzzy logic, can be combined with the model to improve the reliability of decisions.

QFD has been applied in several fields from manufacturing to service environments. Some of researchers have combined fuzzy concepts or AHP to overcome the uncertainty in the assessment process. Halog et al. (2001) utilized the QFD model to determine the emissions that need to be analysed for environmental performance improvement. Partovi \& 


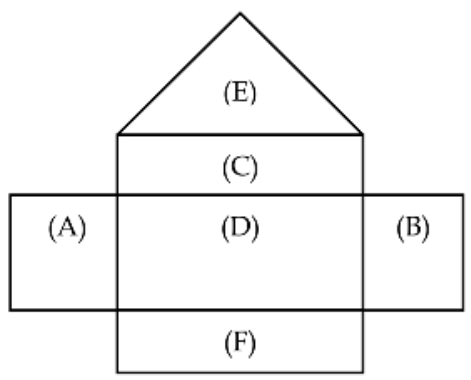
(A) Customer requirements (CR)
(B) Prioritized CR
(C) Design requirements (DR)
(D) Relationship between CR and DR
(E) Interrelationship between DR
(F) Prioritized technical descriptors

Fig. 3. House of quality

Corredoira (2002) presented a model for prioritizing and designing rule changes for the game of soccer. The model is designed based on QFD. In addition, the AHP and analytic network process (ANP) are used to determine the intensity of the relationship between the row and column variables of three matrices. Myint (2003) provided a methodology for the development of the intelligent quality function deployment (IQFD) application in the discrete parts and assembly environment. The method consists of four matrices. Yang et al. (2003) used the house of quality (HOQ) to meet the needs of buildable designs in the construction industry and to develop a fuzzy QFD system for buildable design evaluation. Chan \& Wu (2005) used entropy method instead of using the quite subjective sales-point concept, and derived competitive priority ratings. Furthermore, they utilized triangular fuzzy numbers. Bevilacqua et al. (2006) suggested a new method that transfers the HOQ approach and typical of QFD problems to the supplier selection process. Buyukozkan et al. (2007) also used triangular fuzzy numbers in designing house of quality model. Li \& Kuo (2007) adopted the genetic chaotic neural network (GCNN) technique to identify customer's needs and their priorities and proposed the enhanced QFD. Lee et al. (2008) utilized the fuzzy and Kano models simultaneously to determine the relationship between customer requirements and technical characteristics. Raharjo et al. (2008) applied the ANP in the QFD model to take into account uncertainty in human's judgments. Liu (2009) stated that previous researches have focused on the fuzzy HOQ; however, there are other matrices in the QFD model. They proposed a new model for product planning and part deployment. In addition, they used fuzzy clustering. Hassanzadeh Amin \& Razmi (2009) proposed a general framework for supplier selection, evaluation, and development. They applied a fuzzy HOQ for selecting the best internet service provider (ISP). In addition, they integrated a quantitative model with QFD in order to consider quantitative and qualitative criteria, simultaneously. Utne (2009) applied the HOQ to improve the environmental performance of the fishing fleet. However, he ignored the subjective assessment problem of QFD and used crisp numbers.

In a few papers, QFD is utilized for location selection. Chuang (2002) presented approaches including a single QFD matrix for relating customer wants to facility location. They identified location requirements by sampling. Then, the location evaluating criteria are established from location requirements, and central relationship matrix is filled. Partovi (2006) presented a strategic solution to a facility location problem by using the AHP, ANP, and QFD, concurrently. He considered internal and external criteria. However, these models did not take into account the impression and vagueness of humans' judgments. 
Some researchers have focused on the problem of subjective assessment in QFD. They usually use mathematical models to decrease the imprecision in human's judgements. Temponi et al. (1999) proposed a mathematical model to identify relationships between requirements and overcome the vague data. They utilized fuzzy logic. Kim et al. (2000) developed mathematical models by determining the major model components, such as objectives and constraints in a crisp or fuzzy way using multi attribute value theory combined with the fuzzy regression and fuzzy optimization theory. Tang et al. (2002) proposed two types of fuzzy optimisation models to cover the weaknesses of the QFD model. They utilized a genetic-based interactive approach. Karsak et al. (2002) employed the analytic network process (ANP) to fulfill the relationship between customer requirements $(\mathrm{CR})$ and engineering design requirements (DR). Furthermore, they took into account the multi-objective nature of the problem by incorporating other goals, such as cost, extendibility and manufacturability of PTRs.

Chen \& Weng (2003) developed QFD model by using fuzzy programming to represent the relationships between CR and DR. However, they did not provide a case study. Karsak (2004) presented a multi-objective programming approach that incorporates imprecise and subjective information inherent in the QFD planning process to determine the level of fulfillment of design requirements. In addition, they used triangular fuzzy numbers. According to the difficulties of prioritizing engineering characteristics, Han et al. (2004) suggested a linear partial ordering approach for assessing the knowledge from participants and prioritizing engineering characteristics. Fung et al. (2006) proposed a fuzzy linear regression approach to estimate the functional relationships for product planning based on QFD. In addition, they extended asymmetric triangular fuzzy coefficients to asymmetric trapezoidal fuzzy coefficients using the basic concept of the fuzzy regression. Chen \& Ko (2008) extended the previous model. They presented a fuzzy nonlinear model to determine the performance level of each DR for maximizing customer satisfaction considering Kano's category of design requirements. Delice \& Gungor proposed a new QFD optimization approach combining mixed-integer linear programming and Kano model to determine levels of design requirements. Chin et al. (2009) presented an evidential reasoning (ER) based methodology for synthesizing various types of assessment information provided by a group of customers and multiple QFD team members. They stated that they can overcome the uncertainty in QFD. Zhang \& Chu (2009) proposed a group decision-making approach including two optimization models (i.e., logarithmic and weighted least squares models) to aggregate multi-format and multi-granularity linguistic judgments. They stated that this method can handle subjective assessments. Ramanathan \& Yunfeng (2009) used the data envelopment analysis (DEA) for deriving the relative importance of DRs when several additional factors are considered. They applied the model for the design of security fasteners for a company. Chen \& Ko (2009) proposed fuzzy nonlinear programming models based on Kano's concept to determine the fulfillment levels of part characteristics with the aim of achieving the determined contribution levels of design requirements. Moreover, they used fuzzy numbers.

\section{Fuzzy sets theory}

Nowadays, operations research is applied for solving decision making problems. Unfortunately, real world situations are not often deterministic. As a result, precise mathematical models are not enough to cover practical situations (Lai \& Hwang, 1995). To 
deal with imprecision, the fuzzy set theory (FST) can be used. This concept was proposed by Zadeh (1965). The FST considers the situations involving the human factor with all its vagueness of perception, subjectively, attitudes, goals and conceptions. A membership function of fuzzy sets and operators play a crucial role in the fuzzy set theory. A membership function is a number between 0 and 1, which is denoted by $\mu$ (Zimmermann, 2001).

Triangular fuzzy numbers (TFN) are utilized in the decision making process. A triangular fuzzy number can be denoted by $E=(f, g, h)$ as shown in Fig. 4 . In addition, the membership function is given by Eq. (1). The related results of applying fuzzy arithmetic on the fuzzy numbers, $A=(a, b, c)$ and $E=(f, g, h)$, are as follows (Lai \& Hwang, 1995; Zimmermann, 2001).

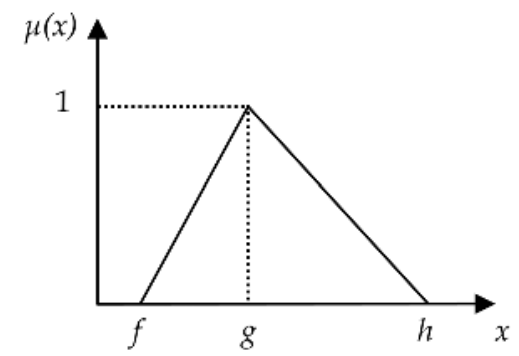

Fig. 4. A triangular fuzzy number

$$
\mu(x)=\left\{\begin{array}{cc}
0, & x<f \\
\frac{x-f}{g-f}, & f \leq x \leq g \\
\frac{h-x}{h-g}, & g \leq x \leq h \\
0, & x>h
\end{array}\right.
$$

i. Addition of two fuzzy numbers

$$
A \oplus E=(a+f, b+g, c+h)
$$

ii. Multiplication of two fuzzy numbers

$$
A \otimes E=(a \times f, b \times g, c \times h)
$$

iii. Multiplication of any number $k$ and a fuzzy number

$$
k \otimes E=(k \times f, k \times g, k \times h)
$$

\section{Problem definition}

A manufacturer wants to establish a new factory. One of the most important factors of this decision is to select the most suitable location. Each location can be considered as an alternative. In addition, the suitable location should be chosen based on several metrics, 
such as facilities and the cost of land. The related criteria consist of both qualitative and quantitative ones. Furthermore, it is important to take into account product characteristics as well as location criteria because product criteria have influence on location selection. For instance, the location of a factory producings heavy products should be close to customers in order to decrease transportation costs.

\section{Proposed model}

In this section, we propose an integrated model to select the best location. The model includes two phases. In the first phase, a collection of alternatives (i.e., locations) is selected based on a set of criteria. The new fuzzy method is applied to overcome the uncertainty. The pre-qualification stage can decrease the time and costs of assessment when a lot of alternatives exist. In the second phase, a fuzzy QFD method is proposed to select the best location. QFD is a unique tool considering the relationship between product and location criteria.

\subsection{Phase 1}

In this pahse, a new method based on linguistic variables and triangular fuzzy numbers (TFNs) is proposed. The output of this stage is a set of qualified locations. First, the members of a decision making group should be selected. Three or five managers can contribute in the decision making process. Suppose that there are $N$ decision makers $(n=1,2, \ldots, N), M$ criteria $(m=1,2, \ldots, M)$, and $K$ qualified locations $(k=1,2, \ldots, K)$. The steps of the proposed algorithm are as follows:

Step 1: Define the proper criteria: the decision making group organizes meeting and determines the appropriate criteria consisting of qualitative and quantitative factors.

Step 2: Let $\mathrm{U}=\{\mathrm{VL}, \mathrm{L}, \mathrm{M}, \mathrm{H}, \mathrm{VH}\}$ be the linguistic set used to express opinions on the group of criteria. The linguistic variables of $U$ can be quantified using triangular fuzzy numbers (please refer to Fig. 5). Each decision maker establishes a level of importance for each criterion by using linguistic variables and TFNs. Then, they are combined by Eq. (5), and the weights of criteria are computed.

$$
w_{m}=\frac{w_{m 1} \oplus w_{m 2} \oplus \ldots \oplus w_{m N}}{N}
$$

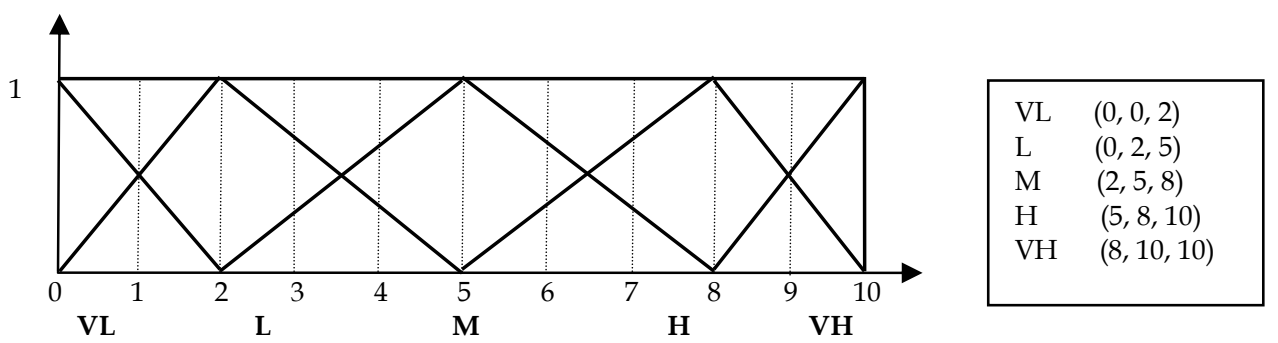

Fig. 5. A linguistic scale for triangular fuzzy numbers

Step 3: Location $k\left(A_{k}\right)$ is assessed based on qualitative criteria. This process is carried out for all alternatives. In other words, decision makers establish the level of importance. Then results are combined by Eq. (6), and aggregated weights are computed that are TFNs. 


$$
A_{m k}=\frac{A_{m k 1} \oplus A_{m k 2} \oplus \ldots \oplus A_{m k N}}{N}
$$

Step 4: In this step, the required data are collected for quantitative attributes, such as the cost of land. Then, the numbers are normalized by Eqs. (7) and (8). The purpose of normalization is to unify the scales of the key factors.

Benefit-criteria normalization:

$$
A_{m k}=\frac{B_{m k}}{\max _{k} B_{m k}} \times 10 \quad m=1,2, \ldots, M \quad k=1,2, \ldots, K
$$

Cost-criteria normalization:

$$
A_{m k}=\frac{\min _{k} B_{m k}}{B_{m k}} \times 10 \quad m=1,2, \ldots, M \quad k=1,2, \ldots, K
$$

Step 5: In this step, the weights of criteria are multiplied by the aggregated weights that are computed in Steps 3 and 4. Eq. (9) displays the formula. In this equation, $a_{k}$ is a TFN. Now, the numbers should be defuzzified. In this chapter, a simple method is applied to defuzzify the numbers. A deffuzzified number of $a_{k}=(a, b, c)$ is calculated by Eq. (10). Now, the locations can be ranked. The result of this step is a collection of the best locations.

$$
\begin{gathered}
a_{k}=\left(w_{1} \otimes A_{1 k}\right) \oplus\left(w_{2} \otimes A_{2 k}\right) \oplus \ldots \oplus\left(w_{M} \otimes A_{M k}\right) \\
b e_{k}=\frac{a+2 b+c}{4}
\end{gathered}
$$

\subsection{Phase 2}

In phase 2, the best location is selected. QFD enables us to consider relationship between product and location characteristics. The main steps of our proposed model are as follows:

Step 1: List customer requirements (CR or product criteria).

Step 2: List design requirements (DR or location criteria).

Step 3: Determine prioritized customer requirement. Each decision maker determines a weight for each CR. Triangular fuzzy numbers are used to quantify the linguistic variables.

Step 4: Determine a weight of each decision maker. Suppose the weight of $\mathrm{DM}_{n}$ is $r_{n}$. This parameter can be determined by a manager of company. These variables are designed according to authority, experience, and the responsibilities of different DMs. In addition, Eq. (11) should be satisfied where $N$ is the number of decision makers $(n=1,2, \ldots, N)$.

$$
\sum_{n=1}^{N} r_{n}=1
$$

Step 5: Calculate the aggregated weight for CR: The assigned weights by the decision makers for customer requirement should be aggregated. The aggregated weight $\left(w_{p}\right)$ is calculated by Eq. (12) where $P$ is the number of CR $(p=1,2, \ldots, P)$.

$$
w_{p}=\left(r_{1} \otimes w_{p 1}\right) \oplus\left(r_{2} \otimes w_{p 2}\right) \oplus \ldots \oplus\left(r_{N} \otimes w_{p N}\right)
$$


Step 6: Determine the relationship between CR and DR. Each decision maker is asked to express opinion by using the linguistic variables on the impact of each DR on each CR. Here again, triangular fuzzy numbers are used to quantify the linguistic variables.

Step 7: Calculate the aggregated weight between CR and DR. The aggregated weight $\left(a_{p m}\right)$ is calculated by the Eq. (13) where $N$ is the number of decision makers $(n=1,2, \ldots, N), P$ is the number of $\mathrm{CR}(p=1,2, \ldots, P)$, and $M$ is the number of DR $(m=1,2, \ldots, M)$.

$$
a_{p m}=\left(r_{1} \otimes a_{p m 1}\right) \oplus\left(r_{2} \otimes a_{p m 2}\right) \oplus \ldots \oplus\left(r_{N} \otimes a_{p m N}\right)
$$

Step 8: Determine prioritized technical descriptors. Now we can complete the matrix by calculating the weights of the DR $\left(f_{m}\right)$, from the aggregated weight for $\mathrm{CR}\left(w_{p}\right)$, and the aggregated weight between $\mathrm{CR}$ and $\mathrm{DR}\left(a_{p m}\right)$ according to Eq. (14). These variables also are triangular fuzzy numbers.

$$
f_{m}=\left(w_{1} \otimes a_{1 m}\right) \oplus \ldots \oplus\left(w_{P} \otimes a_{P m}\right)
$$

Step 9: Determine the impact of each location on the attributes: It is necessary to evaluate locations according to the attributes and combine said assessments with the weight of each attribute in order to establish a final ranking. In the same way as before, the linguistic variables are used to quantify triangular fuzzy numbers, then the location rating (LR) is calculated based on Eq. (15) where $K$ is the number of locations $(k=1,2, \ldots, K)$.

$$
L R_{k m}=\left(r_{1} \otimes l r_{k m 1}\right) \oplus\left(r_{2} \otimes l r_{k m 2}\right) \oplus \ldots \oplus\left(r_{N} \otimes l r_{k m N}\right)
$$

Step 10: Calculate the fuzzy index (FI) that expresses the degree to which a location satisfies a given requirement. The FI is a triangular fuzzy number, which is obtained from the previous scores. Eq. (16) illustrates the formula.

$$
F I_{k}=\frac{1}{M} \otimes\left[\left(L R_{k 1} \otimes f_{1}\right) \oplus \ldots \oplus\left(L R_{k M} \otimes f_{M}\right)\right]
$$

Step 11: Defuzzifiy the numbers and rank the alternatives. Eq. (10) is applied to defuzzify the numbers. Now, the locations can be ranked.

\section{Illustrative example}

In this section, an illustrative example is conducted to show the proposed model. A famous company that manufactures bicycle components, such as cranks, hubs, rims, and so forth wants to establish another factory to expand its supply chain. Therefore, this company should focus on product design during the location selection process. Preliminary investigation shows that eight sites are considered as the most desirable locations. The required data are collected by means of interviews with three experts. Fig. 6 shows the appropriate criteria selected by decision makers for the first phase.

In the first step, decision makers determine the importance of criteria. The results are illustrated in Table 1 . Then the alternatives are assessed based on qualitative factors. Table 2 shows the output of assessment for Location 1. Other locations are assessed in the same way. Then, the required data for quantitative criteria are collected. Table 3 illustrates the assessment process. In the next step, final scores are calculated. The score of Location 1 is illustrated in Table 4 . Then, the triangular fuzzy numbers are defuzzified, and finally the 


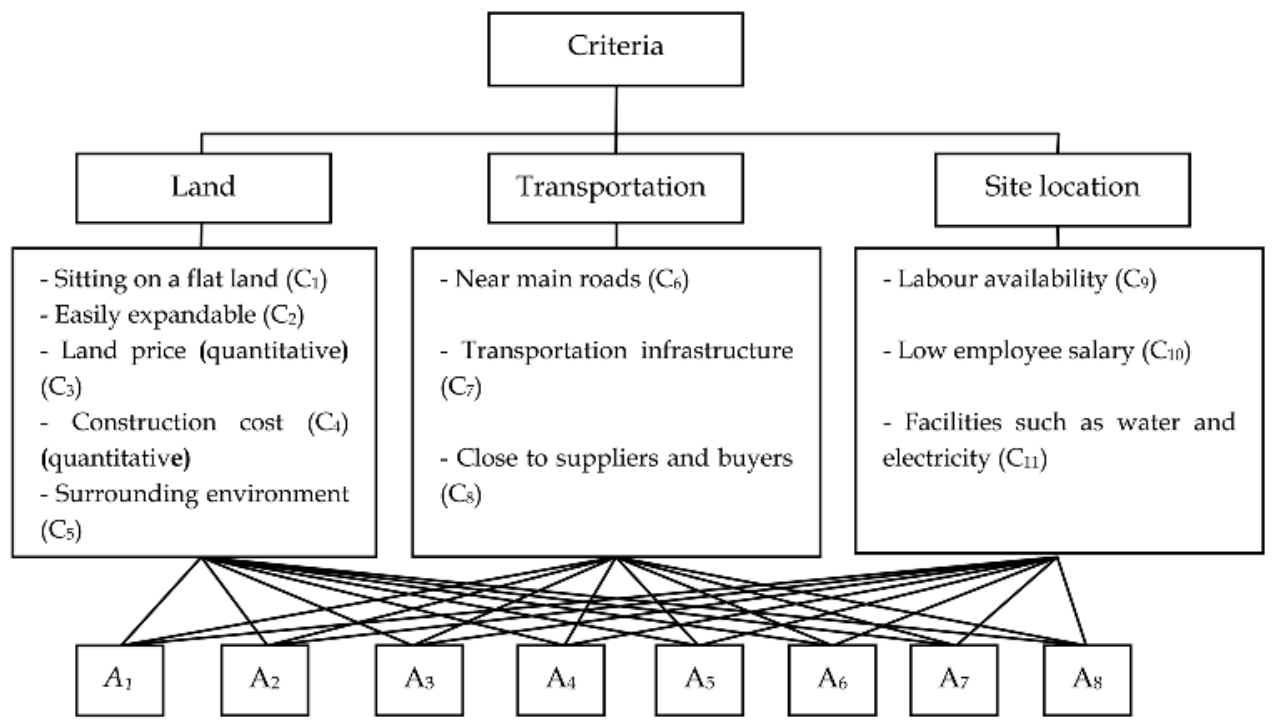

Fig. 6. Location criteria

\begin{tabular}{ccccc}
\hline Criteria & $\mathrm{DM}_{1}$ & $\mathrm{DM}_{2}$ & $\mathrm{DM}_{3}$ & $\begin{array}{c}\text { Weights of } \\
\text { criteria }\left(w_{m}\right)\end{array}$ \\
\hline$C_{1}$ & $\mathrm{M}$ & $\mathrm{M}$ & $\mathrm{L}$ & $(1.3,4,7)$ \\
$C_{2}$ & $\mathrm{M}$ & $\mathrm{H}$ & $\mathrm{H}$ & $(4,7,9.3)$ \\
$C_{3}$ & $\mathrm{VH}$ & $\mathrm{VH}$ & $\mathrm{H}$ & $(7,9.3,10)$ \\
$C_{4}$ & $\mathrm{M}$ & $\mathrm{L}$ & $\mathrm{M}$ & $(1.3,4,7)$ \\
$C_{5}$ & $\mathrm{M}$ & $\mathrm{L}$ & $\mathrm{M}$ & $(1.3,4,7)$ \\
$C_{6}$ & $\mathrm{VH}$ & $\mathrm{H}$ & $\mathrm{H}$ & $(6,8.7,10)$ \\
$C_{7}$ & $\mathrm{H}$ & $\mathrm{H}$ & $\mathrm{H}$ & $(5,8,10)$ \\
$C_{8}$ & $\mathrm{H}$ & $\mathrm{M}$ & $\mathrm{M}$ & $(3,6,8.7)$ \\
$C_{9}$ & $\mathrm{H}$ & $\mathrm{H}$ & $\mathrm{H}$ & $(5,8,10)$ \\
$C_{10}$ & $\mathrm{M}$ & $\mathrm{M}$ & $\mathrm{M}$ & $(2,5,8)$ \\
$C_{11}$ & $\mathrm{H}$ & $\mathrm{VH}$ & $\mathrm{VH}$ & $(7,9.3,10)$ \\
\hline
\end{tabular}

Table 1. Importance of criteria

\begin{tabular}{ccccc}
\hline $\boldsymbol{A}_{1}$ & $\mathrm{DM}_{1}$ & $\mathrm{DM}_{2}$ & $\mathrm{DM}_{3}$ & $\begin{array}{c}\text { Aggregated } \\
\text { weights }\left(\boldsymbol{A}_{m 1}\right)\end{array}$ \\
\hline$C_{1}$ & $\mathrm{M}$ & $\mathrm{L}$ & $\mathrm{M}$ & $(1.3,4,7)$ \\
$C_{2}$ & $\mathrm{~L}$ & $\mathrm{VL}$ & $\mathrm{M}$ & $(0.7,2.3,5)$ \\
$C_{5}$ & $\mathrm{H}$ & $\mathrm{H}$ & $\mathrm{M}$ & $(4,7,9.3)$ \\
$C_{6}$ & $\mathrm{VH}$ & $\mathrm{H}$ & $\mathrm{VH}$ & $(7,9.3,10)$ \\
$C_{7}$ & $\mathrm{~L}$ & $\mathrm{~L}$ & $\mathrm{VL}$ & $(0,1.3,4)$ \\
$C_{8}$ & $\mathrm{M}$ & $\mathrm{M}$ & $\mathrm{L}$ & $(1.3,4,7)$ \\
$C_{9}$ & $\mathrm{H}$ & $\mathrm{H}$ & $\mathrm{M}$ & $(4,7,9.3)$ \\
$C_{10}$ & $\mathrm{H}$ & $\mathrm{VH}$ & $\mathrm{H}$ & $(0,8.7,10)$ \\
$C_{11}$ & $\mathrm{~L}$ & $\mathrm{VL}$ & $\mathrm{L}$ & $(0,1.3,4)$ \\
\hline
\end{tabular}

Table 2. Assessment of location 1 


\begin{tabular}{ccccccccc}
\hline Data & $\boldsymbol{A}_{1}$ & $\boldsymbol{A}_{2}$ & $\boldsymbol{A}_{3}$ & $\boldsymbol{A}_{4}$ & $\boldsymbol{A}_{5}$ & $\boldsymbol{A}_{6}$ & $\boldsymbol{A}_{7}$ & $\boldsymbol{A}_{8}$ \\
\hline $\boldsymbol{C}_{3}$ & 26 & 30 & 31 & 30 & 40 & 25 & 30 & 28 \\
$\boldsymbol{C}_{\boldsymbol{4}}$ & 12 & 15 & 12 & 14 & 10 & 15 & 13 & 13 \\
Normalised & data & & & & & & & \\
$\boldsymbol{C}_{3}$ & 9.6 & 8.3 & 8.1 & 8.3 & 6.3 & 10 & 8.3 & 8.9 \\
$\boldsymbol{C}_{4}$ & 8.3 & 6.7 & 8.3 & 7.1 & 10 & 6.7 & 7.7 & 7.7 \\
\hline
\end{tabular}

Table 3. Assessment of all locations based on quantitative criteria

\begin{tabular}{|c|c|c|c|c|c|c|c|c|c|c|c|c|c|}
\hline & $C_{1}$ & $C_{2}$ & $C_{3}$ & $C_{4}$ & $C_{5}$ & $C_{6}$ & $C_{7}$ & $C_{8}$ & $C_{9}$ & $C_{10}$ & $C_{11}$ & Score & $\begin{array}{c}\text { Defuzzified } \\
\text { score }\end{array}$ \\
\hline$w_{m}$ & 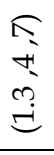 & 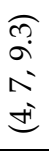 &  & 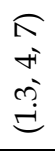 & 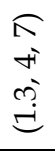 & $\begin{array}{l}\widehat{O} \\
\stackrel{-}{0} \\
\infty \\
0 \\
0\end{array}$ & $\begin{array}{l}\hat{\circ} \\
\infty \\
\infty \\
10\end{array}$ & $\begin{array}{l}\widehat{\sigma} \\
\infty \\
0^{\prime} \\
0^{\prime}\end{array}$ & $\begin{array}{l}\widehat{\circ} \\
\infty^{\circ} \\
0^{\circ}\end{array}$ & 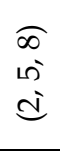 & 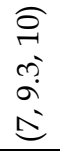 & & \\
\hline$A_{1}$ & 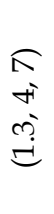 & 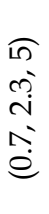 & $\begin{array}{l}6 \\
0 \\
0 \\
0 \\
0 \\
0 \\
i\end{array}$ & $\begin{array}{l}\widehat{\infty} \\
\infty \\
\infty \\
\infty \\
\infty \\
\infty \\
\infty\end{array}$ & $\begin{array}{l}\widehat{\sigma} \\
\text { N } \\
\text { \& }\end{array}$ & 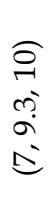 & 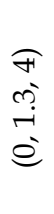 & 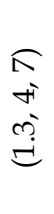 & 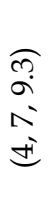 & $\begin{array}{l}\hat{0} \\
\stackrel{-}{1} \\
\infty \\
0 \\
0\end{array}$ & 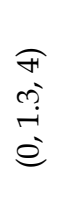 & 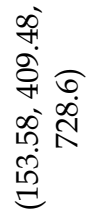 & 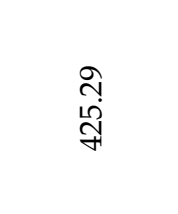 \\
\hline
\end{tabular}

Table 4. Score of Location 1

\begin{tabular}{ccccccccc}
\hline & $A_{1}$ & $A_{2}$ & $A_{3}$ & $A_{4}$ & $A_{5}$ & $A_{6}$ & $A_{7}$ & $A_{8}$ \\
\hline $\begin{array}{c}\text { Defuzzified } \\
\text { score }\end{array}$ & 425.29 & 423.50 & 432.47 & 454.22 & 431.45 & 459.73 & 442.07 & 455.66 \\
\hline Rank & 7 & 8 & 5 & 3 & 6 & 1 & 4 & 2 \\
\hline
\end{tabular}

Table 5. Final ranking for the first phase

locations are ranked. It can be inferred from Table 5 that the best three locations are $A_{6}, A_{8}$, and $A_{4}$. The decision makers evaluate these three alternatives in the second phase.

In the second phase, locations $A_{4}, A_{6}$, and $A_{8}$ are evaluated by the fuzzy QFD method to select the best alternative. Reasonable Cost, Nice Finish, Lightweight, Strength and Durable are chosen as customer requirements. Now, the decision makers should define suitable location criteria. The location criteria include Economic (EC), Technological (TE), Social (SO), Political (PO), and Environmental (EC) factors. The linguistic set is utilized to express the opinions of experts. Each of three decision makers established the level of importance or weight for customer requirements. The related results are shown in Table 6.

The manager of the company has determined a weight for each decision maker. In this example, there are three decision makers. However, one of them has more experience. Therefore, the manager has devoted the weights as $r_{1}=0.4, r_{2}=0.3$, and $r_{3}=0.3$. The aggregated weights are calculated in Table 7, where $P=5, M=5$, and $K=3$. The opinions of three decision-makers, on the impact of each DR on each CR are shown in Table 8. 


\begin{tabular}{lccc}
\hline Customer requirements (CR) & DM $_{\mathbf{1}}$ & $\mathbf{D M}_{\mathbf{2}}$ & $\mathbf{D M}_{\mathbf{3}}$ \\
\hline Reasonable Cost & $\mathrm{H}$ & $\mathrm{L}$ & $\mathrm{M}$ \\
Nice Finish & $\mathrm{L}$ & $\mathrm{M}$ & $\mathrm{H}$ \\
Lightweight & $\mathrm{H}$ & $\mathrm{VH}$ & $\mathrm{H}$ \\
Strength & $\mathrm{H}$ & $\mathrm{M}$ & $\mathrm{H}$ \\
Durable & $\mathrm{M}$ & $\mathrm{L}$ & $\mathrm{L}$ \\
\hline
\end{tabular}

Table 6. Importance of CR

\begin{tabular}{lllll}
\hline CR & $\mathbf{D M}_{\mathbf{1}}$ & $\mathbf{D M}_{\mathbf{2}}$ & $\mathbf{D M}_{\mathbf{3}}$ & \\
\hline$r_{i}$ & 0.4 & 0.3 & 0.3 & Aggregated weights \\
\hline Reasonable Cost & $(5,8,10)$ & $(0,2,5)$ & $(2,5,8)$ & $(2.6,5.3,7.9)$ \\
Nice Finish & $(0,2,5)$ & $(2,5,8)$ & $(5,8,10)$ & $(2.1,4.7,7.4)$ \\
Lightweight & $(5,8,10)$ & $(8,10,10)$ & $(5,8,10)$ & $(5.9,8.6,10)$ \\
Strength & $(5,8,10)$ & $(2,5,8)$ & $(5,8,10)$ & $(4.1,7.1,9.4)$ \\
Durable & $(2,5,8)$ & $(0,2,5)$ & $(0,2,5)$ & $(0.8,3.2,6.2)$ \\
\hline
\end{tabular}

Table 7. Aggregated weight

\begin{tabular}{|c|c|c|c|c|c|c|c|c|c|c|c|}
\hline DR & \multicolumn{4}{|c|}{ Economic (EC) } & \multicolumn{4}{|c|}{ Technical (TE) } & \multicolumn{3}{|c|}{ Social (SO) } \\
\hline CR & $\mathrm{DM}_{1}$ & $\mathrm{DM}_{2}$ & $\mathrm{DM}_{3}$ & & $\mathrm{DM}_{1}$ & $\mathrm{DM}_{2}$ & $\mathrm{DM}_{3}$ & & $\mathrm{DM}_{1}$ & $\mathrm{DM}_{2}$ & $\mathrm{DM}_{3}$ \\
\hline Reasonable & $\mathrm{VH}$ & $\mathrm{H}$ & $\mathrm{H}$ & & $\mathrm{M}$ & $\mathrm{H}$ & $\mathrm{H}$ & & $\mathrm{H}$ & $\mathrm{H}$ & $\mathrm{H}$ \\
\hline Nice Finish & $\mathrm{M}$ & $\mathrm{H}$ & $M$ & & $\mathrm{H}$ & $\mathrm{L}$ & $\mathrm{M}$ & & $\mathrm{L}$ & $M$ & $\mathrm{~L}$ \\
\hline Lightweight & M & $\mathrm{H}$ & $\mathrm{L}$ & & $\mathrm{VH}$ & $\mathrm{VH}$ & $\mathrm{H}$ & & VL & VL & M \\
\hline Strength & M & $\mathrm{H}$ & $\mathrm{H}$ & & M & M & $\mathrm{H}$ & & $\mathrm{L}$ & M & $\mathrm{L}$ \\
\hline Durable & $\mathrm{L}$ & $\mathrm{M}$ & $\mathrm{M}$ & & $\mathrm{H}$ & $\mathrm{H}$ & $\mathrm{H}$ & & $\mathrm{L}$ & $\mathrm{M}$ & $\mathrm{M}$ \\
\hline DR & \multicolumn{4}{|c|}{ Political (PO) } & \multicolumn{7}{|c|}{ Environmental (EN) } \\
\hline CR & & $\mathrm{DM}_{1}$ & $\mathrm{DM}_{2}$ & $\mathrm{DM}_{3}$ & & & $\mathrm{DM}_{1}$ & $\mathrm{DM}_{2}$ & $\mathrm{DM}_{3}$ & & \\
\hline Reasonable Cost & & $\mathrm{L}$ & $\mathrm{M}$ & $\mathrm{M}$ & & & $\mathrm{H}$ & $\mathrm{M}$ & $\mathrm{H}$ & & \\
\hline Nice Finish & & $\mathrm{H}$ & $\mathrm{H}$ & $\mathrm{VH}$ & & & $\mathrm{L}$ & VL & $\mathrm{L}$ & & \\
\hline Lightweight & & $\mathrm{H}$ & M & $\mathrm{H}$ & & & $\mathrm{L}$ & $\mathrm{L}$ & $\mathrm{L}$ & & \\
\hline Strength & & $\mathrm{VH}$ & $\mathrm{H}$ & $\mathrm{H}$ & & & VL & $\mathrm{L}$ & $\mathrm{L}$ & & \\
\hline Durable & & $\mathrm{H}$ & $\mathrm{VH}$ & $\mathrm{H}$ & & & $\mathrm{L}$ & M & $\mathrm{L}$ & & \\
\hline
\end{tabular}

Table 8. Impact of each design requirement (DR) on each customer requirement (CR)

The aggregated weights between CR and DR are calculated. Here again, the $a_{m p}$ elements are triangular fuzzy numbers (Fig. 7). Besides, prioritized technical descriptors are obtained. The fuzzy values are shown in matrix F of Fig. 7. Then, the impact of each potential location on the attributes is considered. Table 9 shows each decision maker's opinions on the various locations in relation to each attribute. Then, location rating is calculated. The FI is calculated by using Eq. (16). The related results are written in Table 10. Furthermore, triangular fuzzy numbers have defuzzified by Eq. (10). Now, the alternatives can be ranked. Ultimate ranking and scores are given in Table 11. According to this table, the eighth alternative (i.e., $A_{8}$ ) is the best one to establish a new factory. 


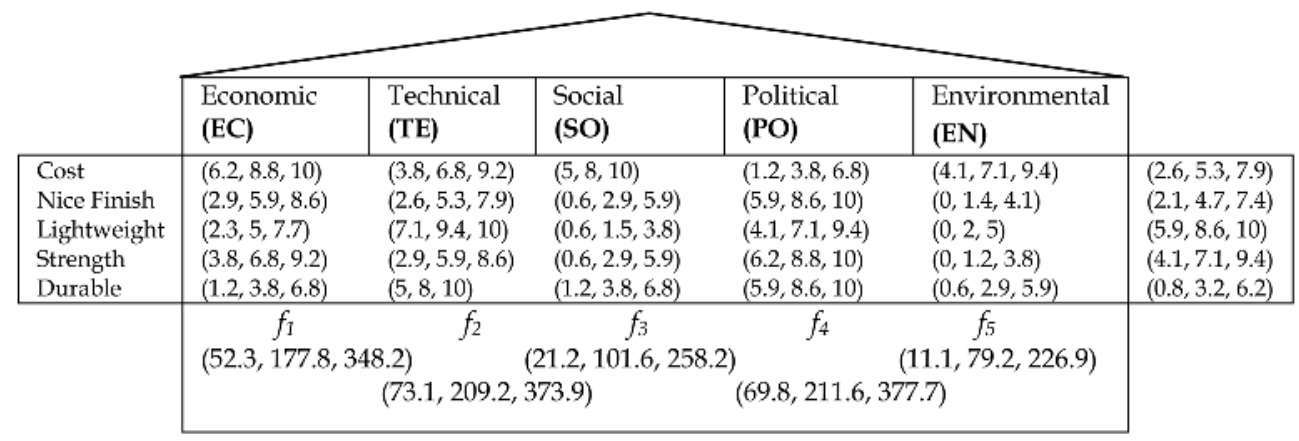

Fig. 7. Completed fuzzy HOQ

\begin{tabular}{|c|c|c|c|c|c|c|c|c|c|c|c|}
\hline DR & \multicolumn{4}{|c|}{ Economic (EC) } & \multicolumn{4}{|c|}{ Technical (TE) } & \multicolumn{3}{|c|}{ Social (SO) } \\
\hline CR & $\mathrm{DM}_{1}$ & $\mathrm{DM}_{2}$ & $\mathrm{DM}_{3}$ & & $\mathrm{DM}_{1}$ & $\mathrm{DM}_{2}$ & $\mathrm{DM}_{3}$ & & $\mathrm{DM}_{1}$ & $\mathrm{DM}_{2}$ & $\mathrm{DM}_{3}$ \\
\hline$A_{4}$ & $\mathrm{~L}$ & VL & $\mathrm{L}$ & & $\mathrm{H}$ & $\mathrm{VH}$ & $\mathrm{H}$ & & $\mathrm{H}$ & $\mathrm{M}$ & $\mathrm{H}$ \\
\hline$A_{6}$ & $\mathrm{~L}$ & $\mathrm{~L}$ & M & & $\mathrm{L}$ & M & $\mathrm{H}$ & & M & $\mathrm{L}$ & M \\
\hline$A_{8}$ & $\mathrm{M}$ & $\mathrm{H}$ & M & & $\mathrm{H}$ & $\mathrm{H}$ & $\mathrm{VH}$ & & $\mathrm{H}$ & $\mathrm{M}$ & $\mathrm{H}$ \\
\hline DR & \multicolumn{4}{|c|}{ Political (PO) } & \multicolumn{7}{|c|}{ Environmental (EN) } \\
\hline CR & & $\mathbf{D M}_{1}$ & $\mathrm{DM}_{2}$ & $\mathrm{DM}_{3}$ & & & $\mathrm{DM}_{1}$ & $\mathrm{DM}_{2}$ & $\mathrm{DM}_{3}$ & & \\
\hline$A_{4}$ & & $\mathrm{H}$ & $\mathrm{H}$ & $\mathrm{H}$ & & & $\mathrm{M}$ & $\mathrm{H}$ & M & & \\
\hline$A_{6}$ & & M & M & $\mathrm{L}$ & & & $\mathrm{H}$ & $\mathrm{H}$ & $\mathrm{H}$ & & \\
\hline$A_{8}$ & & $\mathrm{H}$ & $\mathrm{H}$ & $\mathrm{H}$ & & & VL & $\mathrm{L}$ & $\mathrm{L}$ & & \\
\hline
\end{tabular}

Table 9. Impact of each location on the attributes

\begin{tabular}{llll}
\hline FI & $a$ & $b$ & $c$ \\
\hline$A_{4}$ & 179 & 985 & 2664 \\
$A_{6}$ & 73 & 683 & 2321 \\
$A_{8}$ & 203 & 1071 & 2759 \\
\hline
\end{tabular}

Table 10. Calculation of the FI index

\begin{tabular}{ccc}
\hline & Score & Rank \\
\hline$A_{4}$ & 1204 & 2 \\
$A_{6}$ & 940 & 3 \\
$A_{8}$ & 1276 & 1 \\
\hline
\end{tabular}

Table 11. Defuzzification

\section{Conclusions}

Location selection is a multi-criteria decision making (MCDM) problem. In this chapter, this selection is performed in two phases. In the first phase (i.e., pre-qualification selection), a set of alternatives are selected by the proposed fuzzy method. This method can handle qualitative and quantitative criteria. In the second phase (i.e., final selection), quality function deployment (QFD) is utilized to select the best location. QFD is a unique tool 
considering the relationship between product and location criteria. In addition, linguistic variables and triangular fuzzy numbers are used to overcome the vagueness in human's thought.

In this study, the matrix of the house of quality (HOQ) is applied to select the best alternative. Future research can be performed based on two or more QFD matrices. For instance, the roll of process operations can also be taken into account. Besides, the fuzzy set theory can be replaced by some methods, such as robust and stochastic optimization for determining the relationship between product criteria and engineering design characteristics. It is worth to apply these methods in QFD and compare the efficiency of them.

\section{References}

Berman, O., Drezner, Z., \& Wesolowsky, G. O. (2001). Location of facilities on a network with groups of demand points, IIE Transactions, 33(8), 637-648.

Bevilacqua, M., Ciarapica, F. E., \& Giacchetta, G. (2006). A fuzzy QFD approach to supplier selection, Journal Purchasing and Supply Management, 12(1) 14-27.

Bouchereau, V., \& Rowlands, H. (2000). Methods and techniques to help quality function deployment (QFD), The International Journal of Quality and Reliability Management, 7(1), 8-19.

Buyukozkan, G., Feyzioglu, O., \& Ruan, D. (2007). Fuzzy group decision-making to multiple preference formats in quality function deployment, Computers in Industry, 58(5), 392-402.

Canel, C., Khumawala, B. M., Law, J., \& Loh, A. (2001). Algorithm for the capacitated multicommodity multi-period facility location problem, Computers and Operations Research, 28(5), 411-427.

Chan, L. K., \& Wu, M. L. (2002). Quality function deployment: A literature review, European Journal of Operational Research, 143(3), 463-497.

Chan, L. K., \& Wu, M. L. (2005). A systematic approach to quality function deployment with a full illustrative example, Omega, 33(2), 119-139.

Chen, C. T. (2001). A fuzzy approach to select the location of the distribution center, Fuzzy Sets and Systems, 118(1), 65-73.

Chen, L. H., \& Weng, M. C. (2003). A fuzzy model for exploiting quality function deployment, Mathematical and Computer Modelling, 38(5-6), 559-570.

Chen, L. H., \& Ko, W. C. (2008). A fuzzy nonlinear model for quality function deployment considering Kano's concept, Mathematical and Computer Modelling, 48(3-4), 581-593.

Chen, L. H., \& Ko, W. C. (2009). Fuzzy approaches to quality function deployment for new product design, Fuzzy sets and systems, 160(18), 2620-2639.

Chin, K. S., Wang, Y. M., \& Yang, J. B., \& Poon, K. K. G. (2009). An evidential reasoning based approach for quality function deployment under uncertainty, Expert Systems with Applications, 36(3), 5684-5694.

Chou, T. Y., Hsu, C. L., \& Chen, M. C. (2008). A fuzzy multi-criteria decision model for international tourist hotels location selection, International Journal of Hospitality Management, 27(2), 293-301.

Chuang, P. (2002). A QFD approach for distribution's location model, International Journal of Quality \& Reliability Management, 19(8-9), 1037-1054. 
Cohen, L. (1995). Quality Function Deployment-How to Make QFD Work for You, AddisonWesley Publishing, Reading, MA, UK.

Delice, E. K., \& Gungor, Z. (2009). A new mixed integer linear programming model for product development using quality function deployment, Computers $\mathcal{E}$ Industrial Engineering, 57(3), 906-912.

Fung, R. Y. K., Chena, Y., \& Tang, J. (2006). Estimating the functional relationships for quality function deployment under uncertainties, Fuzzy Sets and Systems, 157(1), 98120.

Guneri, A. F., Cengiz, M., \& Seker, S. (2009). A fuzzy ANP approach to shipyard location selection, Expert Systems with Applications, 36(4), 7992-7999.

Halog, A., Schultmann, F., \& Rentz, O. (2001). Using quality function deployment for technique selection for optimum environmental performance improvement, Journal of Cleaner Production, 9(5), 387-394.

Han, C. H., Kimb, J. K., \& Choi, S. H. (2004). Prioritizing engineering characteristics in quality function deployment with incomplete information: A linear partial ordering approach, International Journal of Production Economics, 91(3), 235-249.

Hassanzadeh Amin, S., \& Razmi, J. (2009). An integrated fuzzy model for supplier management: A case study of ISP selection and evaluation, Expert Systems with Applications, 36(4), 8639-8648.

Hauser, J. R., \& Clausing, D. (1988). The house of quality, Harvard Business Review, (May/June), 63-73.

Heragu, S. S. (2006). Facilities Design, Second edition. iUniverse, Lincoln, NE.

Kahraman, C., Ruan, D., Dogan, I. (2003). Fuzzy group decision-making for facility location selection, Information Sciences, 157, 135-153.

Karsak, E. E., Sozer, S., \& Alptekin, S. E. (2002). Product planning in quality function deployment using a combined analytic network process and goal programming approach, Computers $\mathcal{E}$ Industrial Engineering, 44(1), 171-190.

Karsak, E. E. (2004). Fuzzy multiple objective programming framework to prioritize design requirements in quality function deployment, Computers $\mathcal{E}$ Industrial Engineering, 47(2-3), 149-163.

Kim, K. J., Moskowitz, H., \& Dhingra, A., \& Evans, G. (2000). Fuzzy multi criteria models for quality function deployment, European Journal of Operational Research, 121(3), 504518.

Kuo, R. J., Chi, S. C., \& Kao, S. S. (2002). A decision support system for selecting convenience store location through integration of fuzzy AHP and artificial neural network, Computers in Industry, 47(2), 199-214.

Lai, Y. J., \& Hwang, C. L. (1995). Fuzzy Mathematical Programming: Methods and Applications. Springer-Verlag New York, Inc.

Lee, Y. C., Sheu, L. C., Tsou, Y. G. (2008). Quality function deployment implementation based on Fuzzy Kano model: An application in PLM system, Computers $\mathcal{E}$ Industrial Engineering, 55(1), 48-63.

Li, S. G., \& Kuo, X. (2007). The enhanced quality function deployment for developing virtual items in massive multiplayer online role playing games, Computers $\mathcal{E}$ Industrial Engineering, 53(4) 628-641.

Liu, H. T. (2009). The extension of fuzzy QFD: From product planning to part deployment, Expert Systems with Applications, 36(8), 11131-11144. 
Melkote, S., \& Daskin, M. S. (2001). Capacitated facility location/network design problems, European Journal of Operational Research, 129(3), 481-495.

Myint, S. (2003). A framework of an intelligent quality function deployment (IQFD) for discrete assembly environment, Computers \& Industrial Engineering, 45(2) 269-283.

Nanthavanij, S.,Yenradee, P. (1999). Predicting the optimum number, location, and signal sound level of auditory warning devices for manufacturing facilities, International Journal of Industrial Ergonomics, 24(6), 569-578.

Partovi, F. Y., \& Corredoira, R. A. (2002). Quality function deployment for the good of soccer, European Journal of Operational Research, 137(3), 642-656.

Partovi, F. Y. (2006). An analytic model for locating facilities strategically, Omega, 34(1) 4155.

Raharjo, H., Brombacher, A. C., \& Xie, M. (2008). Dealing with subjectivity in early product design phase: A systematic approach to exploit Quality Function Deployment potentials, Computers $\mathcal{E}$ Industrial Engineering, 55(1), 253-278.

Ramanathan, R., \& Yunfeng, J. (2009). Incorporating cost and environmental factors in quality function deployment using data envelopment analysis, Omega, 37(3), 711723.

Sharma, J. R., Rawani, A. M., \& Barahate, M. (2008). Quality function deployment: a comprehensive literature review, Int. J. Data Analysis Techniques and Strategies, 1(1), 78-103.

Tang, J., Fung, R. Y. K., Xu, B., \& Wang, D. (2002). A new approach to quality function deployment planning with financial consideration, Computers $\mathcal{E}$ Operations Research, 29(11), 1447-1463.

Temponi, C., Yen, J., \& Tiao, W. A. (1999). House of quality: A fuzzy logic-based requirements analysis, European Journal of Operational Research, 117(2), 340-354.

Tzeng, G. H., \& Chen, Y. W. (1999). Optimal location of airport fire stations: a fuzzy multiobjective programming and revised genetic algorithm approach, Transportation Planning and Technology, 23(1), 37-55.

Utne, I. B. (2009). Improving the environmental performance of the fishing fleet by use of Quality Function Deployment (QFD), Journal of Cleaner Production, 17(8), 724-731.

Yang, Y. O., Wang, S. O., Dulaimic, M., \& Lowa, S. P. (2003). A fuzzy quality function deployment system for buildable design decision-makings, Automation in Construction, 12(4), 381-393.

Zadeh, L. A. (1965). Fuzzy sets, Information and Control, 8(1), 338-353.

Zhang, Z., \& Chu, X. (2009). Fuzzy group decision-making for multi-format and multigranularity linguistic judgments in quality function deployment, Expert Systems with Applications, 36(5), 9150-9158.

Zimmermann, H. (2001). Fuzzy set theory and its applications. Boston: Kluwer Academic Publishers. 


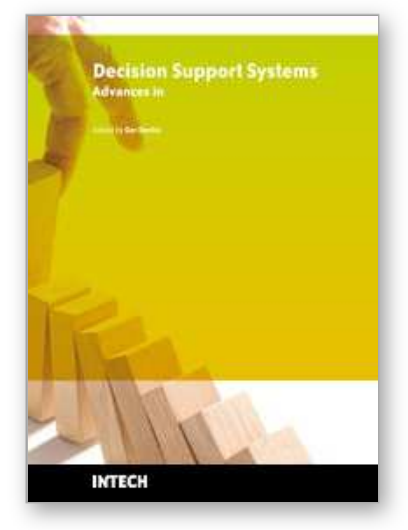

\author{
Decision Support Systems Advances in \\ Edited by Ger Devlin
}

ISBN 978-953-307-069-8

Hard cover, 342 pages

Publisher InTech

Published online 01, March, 2010

Published in print edition March, 2010

This book by In-Tech publishing helps the reader understand the power of informed decision making by covering a broad range of DSS (Decision Support Systems) applications in the fields of medical, environmental, transport and business. The expertise of the chapter writers spans an equally extensive spectrum of researchers from around the globe including universities in Canada, Mexico, Brazil and the United States, to institutes and universities in Italy, Germany, Poland, France, United Kingdom, Romania, Turkey and Ireland to as far east as Malaysia and Singapore and as far north as Finland. Decision Support Systems are not a new technology but they have evolved and developed with the ever demanding necessity to analyse a large number of options for decision makers (DM) for specific situations, where there is an increasing level of uncertainty about the problem at hand and where there is a high impact relative to the correct decisions to be made. DSS's offer decision makers a more stable solution to solving the semi-structured and unstructured problem. This is exactly what the reader will see in this book.

\title{
How to reference
}

In order to correctly reference this scholarly work, feel free to copy and paste the following:

R. Tavakkoli-Moghaddam, S. Hassanzadeh Amin and G. Zhang (2010). A Proposed Decision Support System for Location Selection Using Fuzzy Quality Function Deployment, Decision Support Systems Advances in, Ger Devlin (Ed.), ISBN: 978-953-307-069-8, InTech, Available from: http://www.intechopen.com/books/decisionsupport-systems-advances-in/a-proposed-decision-support-system-for-location-selection-using-fuzzy-qualityfunction-deployment

\section{INTECH}

open science | open minds

\author{
InTech Europe \\ University Campus STeP Ri \\ Slavka Krautzeka 83/A \\ 51000 Rijeka, Croatia \\ Phone: +385 (51) 770447 \\ Fax: +385 (51) 686166 \\ www.intechopen.com
}

\author{
InTech China \\ Unit 405, Office Block, Hotel Equatorial Shanghai \\ No.65, Yan An Road (West), Shanghai, 200040, China \\ 中国上海市延安西路65号上海国际贵都大饭店办公楼 405 单元 \\ Phone: +86-21-62489820 \\ Fax: +86-21-62489821
}


(C) 2010 The Author(s). Licensee IntechOpen. This chapter is distributed under the terms of the Creative Commons Attribution-NonCommercialShareAlike-3.0 License, which permits use, distribution and reproduction for non-commercial purposes, provided the original is properly cited and derivative works building on this content are distributed under the same license. 